\title{
High Cycle Fatigue of ARMCO Iron Severely Deformed by ECAP
}

Jairo Alberto Muñoz ${ }^{1, a}$, Oscar Fabián Higuera ${ }^{1,2, b}$, José María Cabrera ${ }^{1, c}$

${ }^{1}$ Department of Materials Science and Metallurgical Engineering ETSEIB, Universidad Politecnica de Catalunya, Av Diagonal 647, 08028 Barcelona, Spain.

${ }^{2}$ Faculty of Engineering, Mechanical Engineering Program, Universidad del Atlántico, Barranquilla, Colombia

jairo.alberto.munoz@upc.edu, oscarhiguera@mail.uniatlantico.co, jose.maria.cabrera@upc.edu

\begin{abstract}
The high-cycle fatigue behavior of ARMCO iron severely deformed by Equal Channel Angular Pressing (ECAP) at room temperature through route $\mathrm{Bc}$ until 8 passes, with an average grain size of $\sim 365 \mathrm{~nm}$, was studied and compared with the same material in the annealed state with an average grain size of $\sim 72 \mu \mathrm{m}$. The fatigue limit of the 8 passes ECAPed sample increased with respect to the annealed material by more than $250 \%$ rising from $274 \mathrm{MPa}$ to $717 \mathrm{MPa}$. Striations and dimpled relief were observed on the fracture surfaces of the fatigued ultrafine and coarse grain fatigue samples. The microstructure was characterized by Electron Backscattered Diffraction (EBSD) before and after the fatigue tests and it was observed in both samples an increment in the fraction of Low Angle Grain Boundaries (LAGB) at high number of cycles to failure. A texture analysis for the materials after the fatigue failure was done. This study shown a preferential orientation towards the $\gamma$ fiber for both conditions.
\end{abstract}

Keywords: High-Cycle Fatigue (HCF), S-N curve, fatigue limit, Inverse Polo Figure $(I P F)$, Orientation Distribution Function $(O D F)$

\section{Introduction}

Fatigue is associated with the processes of damage accumulation and the resulting fracture of materials under cyclic loading at stress levels below the tensile strength or even the yield stress. The total fatigue life is conventionally divided into two regions corresponding to the times required for crack nucleation and crack propagation. The resistance to crack initiation naturally requires strength, while the tolerance to crack advance requires ductility. The low-cycle fatigue (LCF) and high-cycle fatigue (HCF) regimes are typically distinguished in accordance with the applied strain amplitude. Testing in the HCF regime corresponds to probing the resistance of a material to crack 


\section{ACCEPTED MANUSCRIPT}

initiation, whereas testing in the LCF regime corresponds to assessing the defect tolerance of a material .

There is a great demand for high-strength materials in structural applications in order to obtain light structures. One of the most important methods to achieve this goal is through grain refinement. Ultra fine grained (UFG) materials can be obtained through different techniques, but the so called Equal Channel Angular Pressing (ECAP) is one of the favorite ones because processing can be carried out with no porosity and no contamination. This severe plastic deformation (SPD) technique can enhance both the tensile and fatigue strength at the same time. This is due to the higher resistance to crack initiation of the UFG materials, resulting in an increase in the high-cycle fatigue life .

Up to now, studies on fatigue strength for materials processed by ECAP mainly cover non-ferrous metals, such as copper, aluminum, magnesium, titanium, nickel and their alloys . For that reason, the study of mechanical properties such as high cycle fatigue resistance of ultrafine grain iron is quite important not only because most of the failures in service are attributed to fatigue problems, but also because iron is a base material in the majority of the metallic structures. Therefore, the understanding of its fatigue behavior is important for structural applications and represents the basis for future work with alloyed steels with ultrafine grain sizes.

\section{Experimental procedure}

A commercial ARMCO (acronym from American Rolling Mill Company trademark) iron $\quad(\mathrm{Fe}-0.01 \% \mathrm{C}-0.01 \% \mathrm{Si}-0.059 \% \mathrm{Mn}-<0.01 \% \mathrm{P}-<0.010 \% \mathrm{~S}-0.02 \% \mathrm{Cr}-<0.005 \% \mathrm{Mo}-$ $0.038 \% \mathrm{Ni}-0.013 \% \mathrm{Al}$ (in $\mathrm{wt} \%$ )) was received in the form of $8 \mathrm{~mm}$ in diameter rods. Before ECAP process, the material was annealed in a tubular furnace at $930^{\circ} \mathrm{C}$ for 20 minutes. The rods were divided into short billets with lengths of $\sim 60 \mathrm{~mm}$, which were subjected to severe plastic deformation by ECAP at room temperature up to a maximum equivalent strain of eight (i.e., 1, 2, 3, 4, 5, 6, 7 and 8 ECAP passes) following route Bc. For the ECAP process, a die with an inner angle of $\Phi=90^{\circ}$ and an outer angle of $\psi=$ $37^{\circ}$ was used (see sketch in Figure 1a).

The microstructure and texture of the annealed and deformed samples before and after fatigue tests was characterized by Electron Backscattered Diffraction (EBSD). The 
samples were cut from the centre of the billets and mechanically polished from 2500 grit $\mathrm{SiC}$ paper up to $0.04 \mu \mathrm{m}$ colloidal silica suspension, following standard metallographic procedures. The Oxford Instruments HKL Channel 5 software was used to process the obtained results. The data was analyzed with the HKL software and misorientations lower than $0.5^{\circ}$ were not considered in the post-processing data. The grains were defined using boundaries with misorientations, $\theta$, larger than $15^{\circ}$ and allowing completion down to $10^{\circ}$, while the subgrains were defined by boundaries with misorientation larger than $2^{\circ}$. The orientation distribution functions (ODFs) were calculated by series expansion method using truncation at $\mathrm{L}=22$. Finally, to evaluate the texture change due to the fatigue test the grains of orientations $\langle 110\rangle \| \operatorname{RD}$ or $\langle 111\rangle \|$ ND were isolated considering a tolerance angle of $20^{\circ}$.

The specimens for fatigue and tensile tests were also machined from the annealed and deformed billets. Figure $1 \mathrm{~b}$ and $\mathrm{c}$ shows the dimensions of the samples for every type of test. The tensile tests were performed at room temperature using a constant crosshead velocity of $3.3 \times 10^{-3} \mathrm{~mm} / \mathrm{s}$ until failure in a universal Instron testing machine.

To determine the fatigue S-N curves, 16 samples of the annealed and deformed condition were tested at a load ratio $R=\sigma_{\min } / \sigma_{\max }=0.1$, as shown in Figure 2. Testing frequency was $60 \mathrm{~Hz}$. The first specimen of each condition was tested under monotonic load ( 1 cycle) and the rest of the specimens (15 samples for each condition) were tested at decreasing loads until infinite life was obtained. A resonance machine Rumul Testronic with a capacity of $150 \mathrm{kN}$ was employed for this purpose.

A cycle of fluctuating stresses can be defined by two components: one average or stationary stress $\sigma_{\text {average }}$, and other variable, $\Delta \sigma$. These stresses can be calculated with the following equations :

$$
\begin{gathered}
\sigma_{r}=\sigma_{\max }-\sigma_{\min } \\
\Delta \sigma=\sigma_{r} / 2 \\
\sigma_{\text {average }}=\left(\sigma_{\max }+\sigma_{\min }\right) / 2
\end{gathered}
$$




\section{ACCEPTED MANUSCRIPT}

\section{Results and discussion}

\subsection{Initial microstructure}

Figure 3 exhibits the EBSD maps (Inverse Pole Figures (IPF), and grain boundary nature) obtained from samples after 0 and 8 ECAP passes. The microstructure of the unprocessed material consists of equiaxed grains with an average grain size of $\sim 70 \mu \mathrm{m}$ (grain sizes were determined by the line intercept method), where most of the grain boundaries have misorientations higher than $15^{\circ}$, i.e. they are High Angle Grain Boundaries (HAGB), as displayed in Figure 3b. On the other hand, the material subjected to 8 passes presents a microstructure of shear strained grains surrounded by smaller grains (Figure 3c) with a higher amount of Low Angle Grain Boundaries (LAGB) than for the unprocessed material. It was also apparent that the grain size was reduced to $\sim 400 \mathrm{~nm}$, even though the fraction of HAGB is higher than its LAGB counterpart. According to Tóth et al the grain refinement in UFG materials obtained by SPD techniques at low temperatures is characterized by a continuous dynamic recrystallization process (CDRX), where the grain boundaries do not move as new ones are continuously created from geometrically necessary dislocations (GND).

The GNDs density can be calculated from EBSD measurements . Since GNDs create an orientation gradient in the crystal lattice, their density can be estimated from the orientation differences $\theta$ of neighboring measurement pixels according to:

$$
\alpha b=\theta / b p
$$

where $p$ is the size of a pixel, $b$ is the Burgers vector and $\alpha$ represents the Nye's tensor components.

Due to orientation differences in all three directions between pixels $\alpha$ can be expressed in a matrix form which defines the dislocation density tensor of Nye, where its entrywise norm gives a scalar GND density:

$$
\rho_{G N D}=\frac{1}{b} \sqrt{\alpha_{i j} \alpha_{i j}}
$$

Five components of the Nye tensor can be determined from two-dimensional mapping. From those components a truncated scalar value can be calculated, namely $\rho_{G N D}^{(2 D)}$. 


$$
\rho_{G N D}^{(2 D)}=\frac{1}{b} \sqrt{\alpha_{12}^{2}+\alpha_{13}^{2}+\alpha_{21}^{2}+\alpha_{23}^{2}+\alpha_{33}^{2}}
$$

Figure 4 shows the GND density maps from the EBSD measurements for both annealed and deformed samples before the fatigue tests. The annealed material shows some grouping of GNDs into walls. However the high densities of GNDs are located inside of the grains where, the maximum registered value was $2.7 \cdot 10^{13} \mathrm{~m}^{-2}$ while the average value was $7.11 \cdot 10^{12} \mathrm{~m}^{-2}$. The ARMCO iron processed by eight ECAP passes shows a quite different behavior in the GND map, as the GNDs are grouping into walls, and very close to the current high angle grain boundaries. The maximum density value was $6.5 \cdot 10^{16} \mathrm{~m}^{-2}$, while the average value was $8.7 \cdot 10^{15} \mathrm{~m}^{-2}$. Those high values of GNDs in the ultrafine grain material (after 8 ECAP passes) indicate the great possibility of additional reduction in the grain size, taking into consideration that the GNDs are responsible for the grain subdivision. The high values of GNDs suggest that the steady state in the microstructure has not been reached yet because GNDs control the grain curvature to compensate the grain orientation differences as a consequence of the heterogeneous deformation between grains. For that reason it is expected that further deformation can be introduced in the material. This is similar with the study conducted by A. Pougis et al , where $\mathrm{Cu}$ processed by High Pressure Torsion (HPT) and a total shear strain of $\sim 108$ was necessary to obtain the steady state in the microstructure. The average grain size and GND density obtained in the deformed $\mathrm{Cu}$ were $270 \mathrm{~nm}$ and $2.4 \cdot 10^{9} \mathrm{~m}^{-2}$ respectively. It can be concluded that a low average value of GND density can stop the grain subdivision since the curvature of the grain would be more continuous.

\subsection{Tensile and High-Cycle Fatigue (HCF) properties}

Figure 5 shows the tensile and fatigue curves for the annealed and deformed iron. The tensile tests (Figure 5a) highlight the great difference in strength due to severe plastic deformation through the ECAP process. However, it is also evident the reduction in the ductility of the deformed sample in comparison with its unprocessed counterpart. This loss of ductility is highly related with the reduction in the strain hardening capacity. It has been widely demonstrated that a major grain refinement, down to the nanometer range, may lead to a very high hardness and strength in various metals and alloys, exhibiting a low ductility under tensile testing. This can be explained by the fact that plastic deformation mechanisms associated with the generation and movement of dislocations may not be effective in ultrafine grains. 


\section{ACCEPTED MANUSCRIPT}

One of the most important parameters to increase the strength of UFG materials is the average grain size reduction as predicted by the Hall-Petch equation, which states that the yield stress, $\sigma_{\mathrm{Y}}$, is given by:

$$
\sigma_{Y}=\sigma_{0}+k_{Y} d^{-1 / 2}
$$

where $\sigma_{0}$ defines the friction stress, $\mathrm{d}$ is the average grain size and $k_{Y}$ is a constant of yielding. However, recent studies have shown that UFG materials can exhibit a considerably higher strength than the Hall-Petch prediction in the ultrafine grains range . The nature of such superstrength is associated with other nanostructural feature, such as grain boundary segregation.

By taking into account the influence of two types of boundaries, i.e. HAGB and LAGB, the strengthening contribution to the yield stress can be given by:

$$
\sigma_{Y}=\sigma_{0}+\sigma_{G B}+\sigma_{S G B}=\sigma_{P-N}+\sigma_{S S S}+\sigma_{G B}+\sigma_{S G B}
$$

where $\sigma_{0}$ takes into consideration the strengthening contributions of Peierls-Nabarro stress, $\sigma_{P-N}$, and $\sigma_{S S S}$ accounts for the solid solution strengthening (which can be neglected in this study), and $\sigma_{G B}$ and $\sigma_{S G B}$ are the strengthening contributions from HAGB and LAGB, respectively.

The Peierls-Nabarro stress can be calculated with the following formula :

$$
\sigma_{P-N}=\frac{G}{(1-v)} e^{-2 \pi a / b(1-v)}
$$

where $v$ is Poisson's ratio $(=0.29), a$ is the interplanar spacing of the primary slip $(a=$ $0.2 \mathrm{~nm}), G$ is the shear modulus for $\mathrm{Fe}(G=82 \mathrm{GPa})$ and $b$ is the Burgers vector $(=0.248 \mathrm{~nm})$. Although depending of the alloy, some authors neglects $\sigma_{P-N}$ this is not the case for iron bcc, which according to according to equation (9) takes a value of $\sim 91 \mathrm{MPa}$.

EBSD analysis also enables an evaluation of LAGBs contribution to the increase of strength. This can be treated as dislocation strengthening (Taylor strengthening) : 


$$
\sigma_{S G B}=\alpha G M b \sqrt{\rho_{0}+\rho_{L A G B}}
$$

where $M$ is the Taylor factor (3.06 calculated from EBSD measurements), $\alpha$ is a factor taken as $0.3, \rho_{0}$ is the dislocation density between boundaries for the annealed condition taken as $\rho_{0}=10^{12} \mathrm{~m}^{-2}$, and $\rho_{L A G B}$ is the dislocation density stored in LAGBs (subgrains) estimated by :

$$
\rho_{L A G B}=\frac{3(1-f) \bar{\theta}_{L A G B}}{b L}
$$

where $f$ is the HAGB fraction, $\bar{\theta}_{L A G B}$ the average misorientation of the LAGB and $L$ the average boundary spacing of subgrains, taking $2^{\circ}$ as the critical misorientation angle. All of them, listed in Table 1, were calculated following the procedures described in literature . In addition, the strengthening contribution from the HAGB follows the HallPetch relationship as:

$$
\sigma_{G B}=k\left(\frac{f}{d}\right)^{1 / 2}
$$

The $k$ value was determined in a previous study to be $0.36 \mathrm{MPa} \mathrm{m}^{1 / 2}$. One can obtain the strength contributing factors (Table 1 ) by substituting the parameter values into equations (10), (11) and (12). Each one of the contributions for the yield stress are compared in Figure 6 with the experimental strength, and a good correlation between the experimental and calculated strengths can be observed.

The mayor contribution to the material strength is coming from the HAGB, for the processed material. However, an increase in the amount of the LAGB contribution can be seen in Figure 6 for the severely deformed material, which can be explained by the reduction in the grain size (as a consequence of the great deformation introduced during the ECAP process due to the fragmentation of the initial coarse grains by the generation of new subgrains which will evolve into grains with the increase in the deformation). This is in agreement with the investigation of Valiev et al., where it was pointed out that the presence of non-equilibrium grain boundaries is typical for the majority of SPD materials. However, their influence on mechanical properties becomes considerable when the grain size is below $500-1000 \mathrm{~nm}$. 


\section{ACCEPTED MANUSCRIPT}

The fatigue curves ( $\mathrm{S}-\mathrm{N}$ curves) for both materials are displayed in Figure 5b. The ARMCO iron processed by eight ECAP passes presents a big increment (>190\%) in the fatigue strength. According to the literature, ultrafine structures usually exhibit higher fatigue resistance than materials with a conventional grain size under stress-controlled loading. For example, the fatigue life and endurance limit at constant stress amplitude cycling of $\mathrm{Ni}$ and an $\mathrm{Al}-\mathrm{Mg}$ alloy increase when the microstructure changes from microcrystalline to UFG and nanocrystalline. Since HCF is more depend on the strength of materials than on the ductility, a better performance of the material with eight passes is expected. The Basquin equation was used to better understand the increase in the fatigue strength. This equation shows a relationship between the stress amplitude and the number of cycles to failure as follows:

$$
\sigma=A * N_{F}^{-b}
$$

where $A$ is the fatigue resistance coefficient, $b$ is the fatigue resistance exponent and $N_{F}$ is the number of cycles. The calculated parameters after fitting this equation are shown in Table 2. The values of the fatigue resistance coefficient $(A=284.66 \mathrm{MPa}$ and $A=872.97 \mathrm{MPa}$ for the annealed and eight ECAP passes specimens respectively) confirm once again the increase in the fatigue strength for the ECAPed material. On the other hand the similar values of the fatigue resistance exponent $(b=0.06$ and $b=0.07$ for the annealed and eight ECAP passes specimens respectively) are in good agreement with the behavior observed in Figure $5 \mathrm{~b}$, where both materials present rather similar slopes. The value of the fatigue strength for the ECAP processed material is lower than for a low carbon steel processed by High Pressure Torsion (HPT) but higher than those obtained in $\mathrm{Cu}$ and $\mathrm{Al}$. The differences are attributed to different values of tensile strength after severe plastic deformation. Therefore, the low carbon steel processed by HPT reached a higher reduction in the grain size that present iron while $\mathrm{Cu}$ and $\mathrm{Al}$ present lower tensile strength than iron leading to higher and lower HCF strength than iron respectively.

As the fatigue behavior of nanomaterials cannot simply be explained by the Hall-Petch effect, several aspects such as microstructural stability, shear banding, or grain size distributions are some of the key parameters to explain their behavior. For that reason, in Figure 7 and Figure 8 the microstructures before and after fatigue together with their 


\section{ACCEPTED MANUSCRIPT}

properties are shown respectively. To better understand the microstructural evolution of the two tested conditions (ultrafine and coarse grain size), two points over the fatigue curves have been analyzed for each material. Samples were taken close to the fracture area in the TD plane (see Figure 1).

The EBSD maps obtained for each point over the HCF curve can be seen in Figure 7. A marked change in the microstructure morphology is observed, especially for the material with eight ECAP passes at high number of cycles, but also for the annealed material at low number of cycles. It is also evident in Figure 7 a change in the material texture after the fatigue test. According with the IPF representation most of the grains present a preferential orientation towards the $\langle 101\rangle$ direction, especially the sample processed by ECAP.

The microstructural properties (grain size, aspect ratio and \%HAGB) are presented in Figure 8, where two different behaviors can be distinguished. The first one corresponds to the annealed material and shows a reduction in the grain size and the fraction of HAGB, while the second one highlights an increase in the grain size and the fraction of HAGB for the ECAP processed material up to eight passes. In the microstructures presented in Figure 8 a change in the grains morphology can be identified, which can be correlated with the increase in the aspect ratio values (Figure 8b). It has been shown by Vinogradov et. al. that cyclic softening, grain growth, and strain localization appear to be the main mechanisms responsible for the lower fatigue resistance of UFG structures under the same plastic strain amplitude. In this way, those mechanisms seem to be responsible for the reduction in the fatigue resistance, especially for the annealed sample. It was noted that pressing through an increasing number of passes in ECAP leads to an increase of the monotonic strength and fatigue limit .

The fracture surfaces have been also analyzed in Figure 9 for both conditions. In both cases, and at low number of cycles, a more tensile type fracture surface is shown, with a great amount of dimples and intense plastic deformation around it. This behavior is in accordance with the elongation percentages obtained during tensile tests (Figure 5a), where the annealed sample presented higher ductility values. On the other hand the fracture areas after a number of cycles of approximately $2 \cdot 10^{6}$, present fatigue characteristic features, where three zones can be easily identified: the crack nucleation and growth, its propagation and the material fracture. 


\section{ACCEPTED MANUSCRIPT}

\subsection{Texture and microstructure after fatigue}

Recrystallization together with grain growth have been reported to occur in UFG materials during fatigue tests, when a microstructure consisting of mainly elongated subgrains or lamellar subgrains has been observed. All those microstructural characteristics are in good agreement with the behavior of the ARMCO iron after HCF tests. Figure $8 \mathrm{a}$ and $8 \mathrm{~b}$ shows the increment in the grain size together with a large increment in the aspect ratio for the material with eight ECAP passes. The increment in the aspect ratio is consistent with the elongated grains and subgrains that appear in the microstructure after the fatigue test, as observed in Figure 7.

To characterize the texture of the material, it is important to know the ideal texture orientations. In this case the ideal components for BCC materials deformed by conventional methods and by simple shear are summarized in Figure 10 and also in Table 3.

In order to identify the initial symmetry, the material in this investigation was analyzed in monoclinic symmetry. Figure 11 and Figure 12 show the ODFs for the annealed and eight ECAP passes samples respectively, where the grains are colored in red and green to represent the orientations belonging to the $\gamma$ and $\alpha$ fibers respectively. It was observed that the two materials present a repetitive behavior of the texture after $\phi_{1}=90^{\circ}$, corresponding to an orthorhombic symmetry $\left(0^{\circ}<\phi_{1}<90^{\circ}\right)$.

The texture evolution in the annealed material (Figure 11 and Figure 13) shows a higher orientation of the grains along the $\gamma$ fiber than on the $\alpha$ fiber. However, after the fatigue test the opposite happens for the samples processed with 8500 cycle and with 1537900 cycles. This behavior is similar with other observations of an Interstitial Free (IF) steel after annealing, where it was observed that the recrystallization orientations were generally close to the $\alpha$ and $\gamma$ fibres, but that much of the $\alpha$ fibre had been eliminated

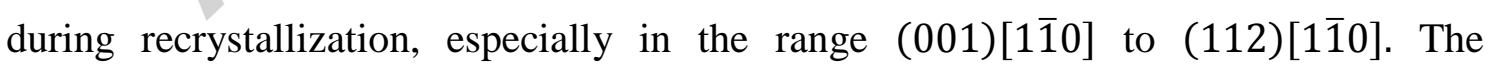
reduction of the $\alpha$ fiber was also observed in the initial ARMCO iron sample before fatigue (Figure 13). After fatigue, the annealed material shows a texture typical of a cold worked material, where the $\alpha$ fiber is more representative than the $\gamma$ fiber. Therefore, most of the grains are oriented towards the direction of load application during the fatigue test, as seen in Figure 11. 


\section{ACCEPTED MANUSCRIPT}

For the sample processed by eight ECAP passes an initial texture due to the severe plastic deformation is observed (Figure 12 and Figure 14). The texture was defined according to the ideal orientations suggested by Beyerlein et al. and $\mathrm{Li}$ et al., which are summarized in Table 3. As shown in Figure 14, the strongest components are $\mathrm{D}_{1}$ and $\mathrm{D}_{2}$ followed by $\mathrm{F}, \mathrm{J}, \overline{\mathrm{J}}, \mathrm{E}$ and $\overline{\mathrm{E}}$ respectively. However, the texture changed after the fatigue test, as noticed in Figure 12 and Figure 13, where a stronger presence of the $\gamma$ and $\alpha$ fibers, especially in the case of the $\alpha$ fiber, is apparent. This change in texture for the material with eight passes is correlated to Figure 14 where the reduction in the intensity of all the simple shear components is clearly observed. According to Engler et al. BCC materials tend to form $\langle 110\rangle$ fiber textures under uniaxial tension and drawing. This could explain the elongated grains observed in Figure 12 for the material with eight ECAP passes, as a state of plane strain on the grain level is favored.

The main components developed in the deformed material after fatigue are (111)[110] and (111)[0 $\overline{1} 1]$ in the $\gamma$ fiber, whereas in the $\alpha$ fiber the strongest component is (332)[1 10$]$, as shown in Figure 13. This behavior is similar to the one reported by Bonnot et al. [46] for ARMCO iron processed by 7 cycles of Accumulative Roll Bonding (ARB) with a strong (111)[110] component. It has been shown by Gobernado et al. that this component raises a particular interest for magnetic applications. The texture of the material after eight ECAP passes plus fatigue is similar to the rolling texture of a low carbon steel, where the increasing rolling deformation tends to shift the texture maximum from $\{001\}\langle 110\rangle$ along the $\alpha$ fiber over $\{112\}\langle 110\rangle$ and toward $\{111\}\langle 110\rangle$ in the $\gamma$ fiber, as displayed in Figure 13.

To understand the effect of crystallographic orientation on the formation of HAGB, the evolution of HAGB fraction has been calculated both for $\langle 110\rangle \| \mathrm{RD}$ and $\langle 111\rangle \| \mathrm{ND}$ grain orientation, respectively for the $\alpha$ and $\gamma$ fibers usually observed in BCC materials. The results are indicated in Figure 15. It appears that HAGB are produced in a higher fraction in the $\alpha$ fiber than in the $\gamma$ fiber. It is important to note that the difference between the HAGB fraction in the $\alpha$ fiber and in the $\gamma$ fiber is more pronounced for the material with eight ECAP passes. This is due to the gradual rotation of the $\alpha$ fiber components towards two specific components: $\{111\}\langle 110\rangle$ and $\{332\}\langle 110\rangle$. This is at the origin of HAGB formation inside the $\alpha$ fiber that becomes mainly composed of two components: $\{111\}\langle 110\rangle$ and $\{332\}\langle 110\rangle$ misorientated by $10^{\circ}$. 


\section{ACCEPTED MANUSCRIPT}

\section{Conclusions}

A noticeable reduction in the grain size was observed between the initial material and the material after eight ECAP passes. This behavior is a consequence of the continuous generation of new grain boundaries from the grouping of dislocations until the formation of subgrains which finally evolves in grain boundaries with the future strain. As a consequence of the reduction in the grain size, the material after eight ECAP passes presented a considerable increment in the tensile strength as well as for the HCF strength (>190\% in increment) with respect to the annealed material, where the main contribution to the tensile strength was coming from the HAGB according with the modified Hall-Petch relationship. However, an important reduction in the ductility of the processed material was also observed. This reduction was attributed to the lost in the strain hardening capability of the material.

The study of the microstructures after the fatigue tests for both materials (zero and eight passes) showed some changes with respect to the materials before the fatigue test. Initially a marked change in the microstructure morphology is observed, especially for the material with eight ECAP passes at high number of cycles, but also for the annealed material at low number of cycles. The annealed material showed a reduction in the grain size and the fraction of HAGB, while the processed one highlights an increase in the grain size and the fraction of HAGB. It is also evident a change in the material texture after the fatigue test where most of the grains present a preferential orientation towards $<101>$ direction, especially the sample processed by ECAP.

A clear increment in the fraction of grains oriented towards the $\gamma$ and $\alpha$ fiber was noticed in both conditions after the fatigue tests. The main components developed in the deformed material after fatigue were (110)[1 $\overline{1} 0]$ and (111)[0 $\overline{1} 1]$ in the $\gamma$ fiber, whereas in the $\alpha$ fiber the strongest component was(332)[110]. It was also found that HAGB were produced in a higher fraction in the $\alpha$ fiber than in the $\gamma$ fiber specially for the material with eight ECAP passes.

\section{Acknowledgements}

JAMB thanks the FPU scholarship received by the Spanish Education Ministry. Authors also thank the support of the mechanical testing service of Fundació CTM centre Tecnológic, especially from Mr. Eduard Pla. 


\section{ACCEPTED MANUSCRIPT}

\section{References}

[1] S. Suresh, Fatigue of Materials, Cambridge: Cambridge University Press, 1991.

[2] J. Polark, Cyclic Plasticity and Low Cycle Fatigue Life of Metals, Amsterdam: Elsevier, 1991.

[3] R. Z. Valiev, A. P. Zhilyaev and T. G. Langdon, "Mechanical Properties of BNM at Ambient Temperature," in Bulk Nanostructured Materials, John Wiley \& Sons, Inc, 2013, pp. 331-356.

[4] R. Z. Valiev and T. G. Langdon, Prog. Mater. Sci. , vol. 51, pp. 881-981, 2006.

[5] S. Qu, X. H. An, H. J. Yang, C. X. Huang, G. Yang, Q. S. Zang, Z. G. Wang, S. D. Wu and Z. F. Zhang, Acta Mater, vol. 57, p. 1586-1601, 2009.

[6] Y. Estrin and A. Vinogradov, Int. J. Fatigue, vol. 32, p. 898-907, 2010.

[7] M. Okayasu, K. Sato, M. Mizuno, D. Y. Hwang and D. H. Shin, Int. J. Fatigue, vol. 30, p. 1358-1365, 2008.

[8] H. Ueno, K. Kakihata, Y. Kaneko, S. Hashimoto and A. Vinogradov, Acta Mater, vol. 59, p. 7060-7069, 2011.

[9] C. Z. Xu, Q. J. Wang, M. S. Zheng, J. W. Zhu, J. D. Li, M. Q. Huang, Q. M. Jia and Z. Z. Du, Mater. Sci. Eng. A, vol. 459, p. 303-308, 2007.

[10] V. Patlan, A. Vinogradov, K. Higashi and K. Kitagawa, Mater. Sci. Eng. A, vol. 300, p. 171, 2001.

[11] X. H. An, W. Z. Han, C. X. Huang, P. Zhang, G. Yang, S. D. Wu and Z. F. Zhang, Appl. Phys. Lett., vol. 92, p. 201915., 2008.

[12] C. Z. Xu, Q. J. Wang, M. S. Zheng, J. W. Zhu, J. D. Li, M. Q. Huang, Q. M. Jia y Z. Z. Du, Mater. Sci. Eng. A, vol. 459, p. 303-308, 2007.

[13] H. Mughrabi and H. W. Höppel, Int J. Fatigue, vol. 32, p. 1413-1427, 2010.

[14] G. E. Dieter, Mechanical Metallurgy, McGraw Hill, 1988.

[15] L. S. Toth and C. Gu, "Ultrafine-grain metals by severe plastic deformation," Materials Characterization, vol. 92, pp. 1-14, 2014.

[16] W. Pantleon, "Resolving the geometrically necessary dislocation content by conventional electron backscattering diffraction," Scripta Materialia, vol. 58, no. 11, pp. 994-997, 2008. 


\section{ACCEPTED MANUSCRIPT}

[17] A. Pougis, L. S. Toth, J. J. Fundenberger and A. Borbely, Scripta Materialia, Vols. 72-73, pp. 59-62, 2014.

[18] D. G. Morris, Mechanical Behaviour of Nanostructured Materials, Uetikon-Zurich: Trans Tech, 1998.

[19] C. C. Koch, Scr Mater, vol. 49, p. 657, 2003.

[20] N. J. Petch, J Iron Steel Inst, vol. 174, p. 25, 1953.

[21] R. Z. Valiev, N. A. Enikeev, M. Muraskin, V. U. Kazykhanov and X. Sauvage, Scr Mater, vol. 63, p. 949, 2010.

[22] R. Z. Valiev y T. G. Langdon, Adv Eng Mater, vol. 12, p. 677, 2010.

[23] J. N. Wang, Mater. Sci. Eng. A, vol. 206, pp. 259-269, 1996.

[24] F. R. N. Nabarro, Mater. Sci. Eng. A, vol. 234, pp. 67-76, 1997.

[25] P. Rodríguez-Calvillo, N. Ferrer and J. M. Cabrera, Journal of Alloys and Compounds, vol. 626, pp. 340-348, 2015.

[26] P. Luo, D. T. McDonald, W. Xu, S. Palanisamy, M. S. Dargusch and K. Xia, Scripta Mater, vol. 66, pp. 785-788, 2012.

[27] P. Luo, D. T. McDonald, S. M. Zhu, S. Palanisamy, M. S. Dargusch and K. Xia, Mater. Sci. Eng. A, vol. 538, pp. 252-258, 2012.

[28] F. R. N. Nabarro, Z. S. Basinski and D. B. Holt, Adv. Phys, vol. 13, p. 193, 1964.

[29] Y. Bergstrom, "A dislocation model for stress-strain behavior of polycrystalline alfa-Fe with special emphasis on the variation of the densities of mobile and immobile dislocations," Mater. Sci. Eng, vol. 5, pp. 193-202, 1969/70.

[30] D. A. Hughes and N. Hansen, Acta Mater, vol. 48, p. 2985, 2000.

[31] J. Muñoz Bolaños, O. Higuera Cobos and J. Cabrera Marrero, "Strain hardening behavior of ARMCO iron processed by ECAP," IOP Conf. Ser.: Mater. Sci. Eng, vol. 63, p. 012143, 2014.

[32] R. Z. Valiev, E. V. Kozlov, Y. F. Ivanov, J. Lian, A. A. Nazarov and B. Baudelet, Acta Metall Mater, vol. 42, p. 2467, 1994.

[33] T. Hanlon, Y. N. Kwon and S. Suresh, Scr Mater, vol. 49, p. 675, 2003.

[34] R. Z. Valiev, A. P. Zhilyaev and T. G. Landon, "Mechanical Properties of BNM at Ambient Temperature," in Bulk Nanostructured Materials: Fundamentals and 


\section{ACCEPTED MANUSCRIPT}

Applications, New Jersey, John Wiley \& Sons, Inc, 2014, pp. 332-334.

[35] C. Ruffing, Y. Ivanisenko and E. Kerscher, "Fatigue behavior of ultrafine grained medium carbon steel processed by severe plastic deformation," IOP Conf. Series: Materials Science and Engineering, vol. 63, p. 012163, 2014.

[36] O. F. Higuera Cobos, Relación microestructura y propiedades de cobre sometido a deformación plástica severa mediante presión en canal angular de sección constante, Barcelona: Tesis Doctoral, 2013.

[37] L. Hollang, E. Hieckmann, D. Brunner, C. Holste and W. Skrotzki, Mater. Sci. Eng. A, vol. 424, p. 138, 2006.

[38] R. Valiev, R. Islamgaliev and I. Alexandrov, Prog Mater Sci, no. 45, p. 103, 2000.

[39] H. W. Hoeppel, H. Mughrabi and A. Vinogradov, in Bulk Nanostructured Materials, M. J. Zehetbauer and Y. T. Zhu, Eds., Weinheim, Wiley-VCH Verlag GmbH \& Co, 2009, p. 481.

[40] A. Y. Vinogradov and S. R. Agnew, in Dekker Encyclopedia of Nanoscience and Nanotechnology, New York, Marcel Dekker Inc, 2004, p. 2269.

[41] A. Vinogradov, Y. Suzuki, V. I. Kopylov, V. Patlan and K. Kitagawa, Acta Metall, vol. 50, p. 1636, 2002.

[42] A. Vinogradov and S. Hashimoto, Adv Eng Mater, vol. 5, p. 351, 2003.

[43] A. Vinogradov and S. Hashimoto, Mater Trans, vol. 42, p. 74, 2001.

[44] F. Humphreys and M. Hatherly, Recrystallization and related annealing phenomena, Pergamon, 1996.

[45] S. Li and I. J. Beyerlein, Model Simul Mater Sci Eng, vol. 13, p. 509, 2005.

[46] W. B. Hutchinson and L. Ryde, in In: Thermomechanical processing (TMP2), H. e. al, Ed., Ohio, ASM, 1997, p. 145.

[47] I. J. Beyerlein and L. S. Tóth, Progress in Materials Science, vol. 54, pp. 427-510, 2009.

[48] O. Engler and V. Randle, Introduction to Texture Analysis: Macrotexture, Microtexture, and Orientation Mapping, CRC Press, 2009.

[49] E. Bonnot, A.-L. Helbert, F. Brisset and T. Baudin, Materials Science \& Engineering A, vol. 561, pp. 60-66, 2013. 


\section{ACCEPTED MANUSCRIPT}

[50] P. Gobernado, R. Petrov, D. Ruiz, E. Leunis and I. A. I. Kestens, Adv. Eng. Mater, vol. 12, pp. 1077-1081, 2010.

[51] M. Hölscher, D. Raabe and K. Lücke, Steel Res, vol. 62, p. 567, 1991.

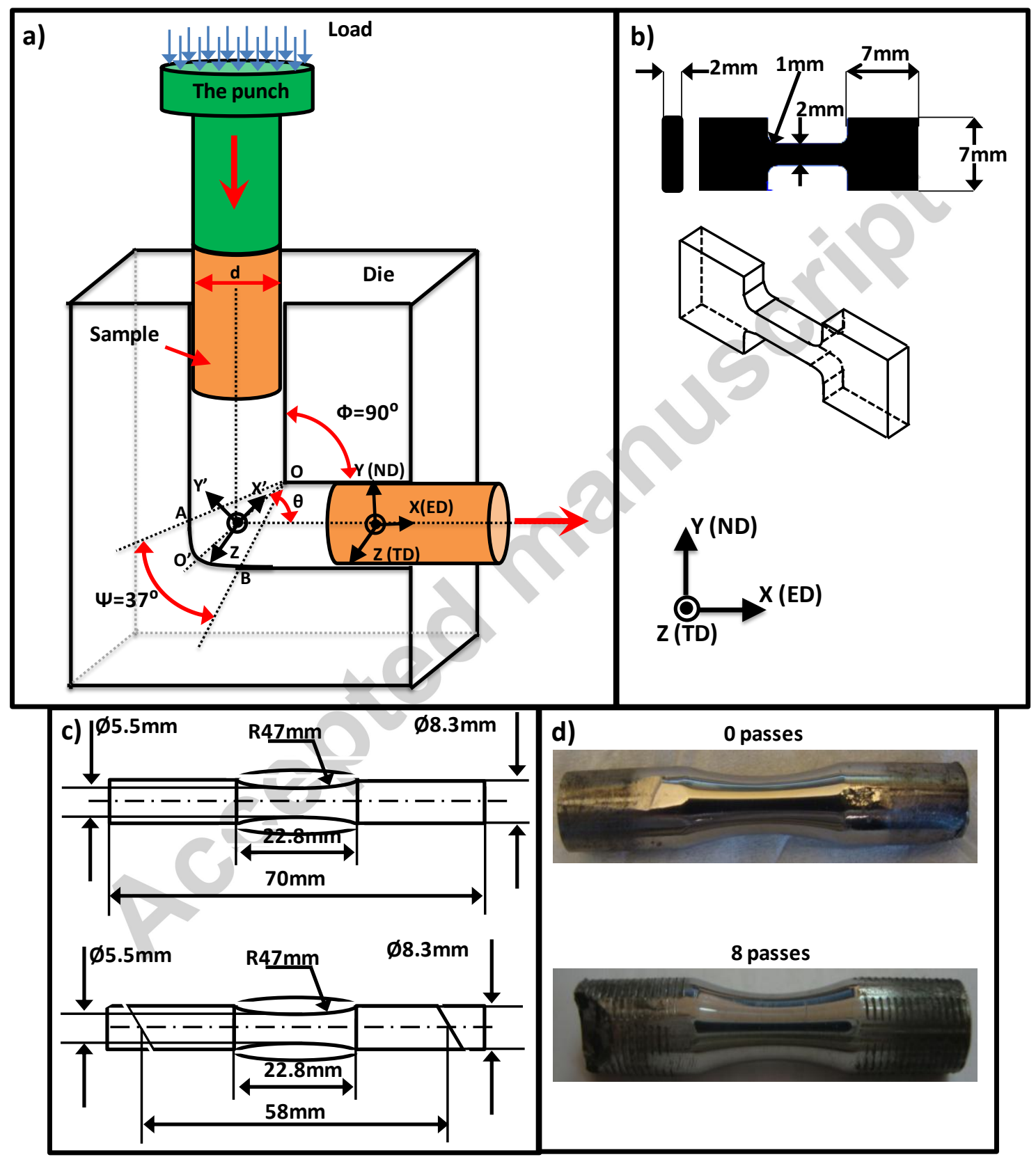

Figure 1. a) ECAP die configuration, b), c) and d) Dimensions of the tensile and fatigue samples for the annealed and eight ECAP passes condition. 


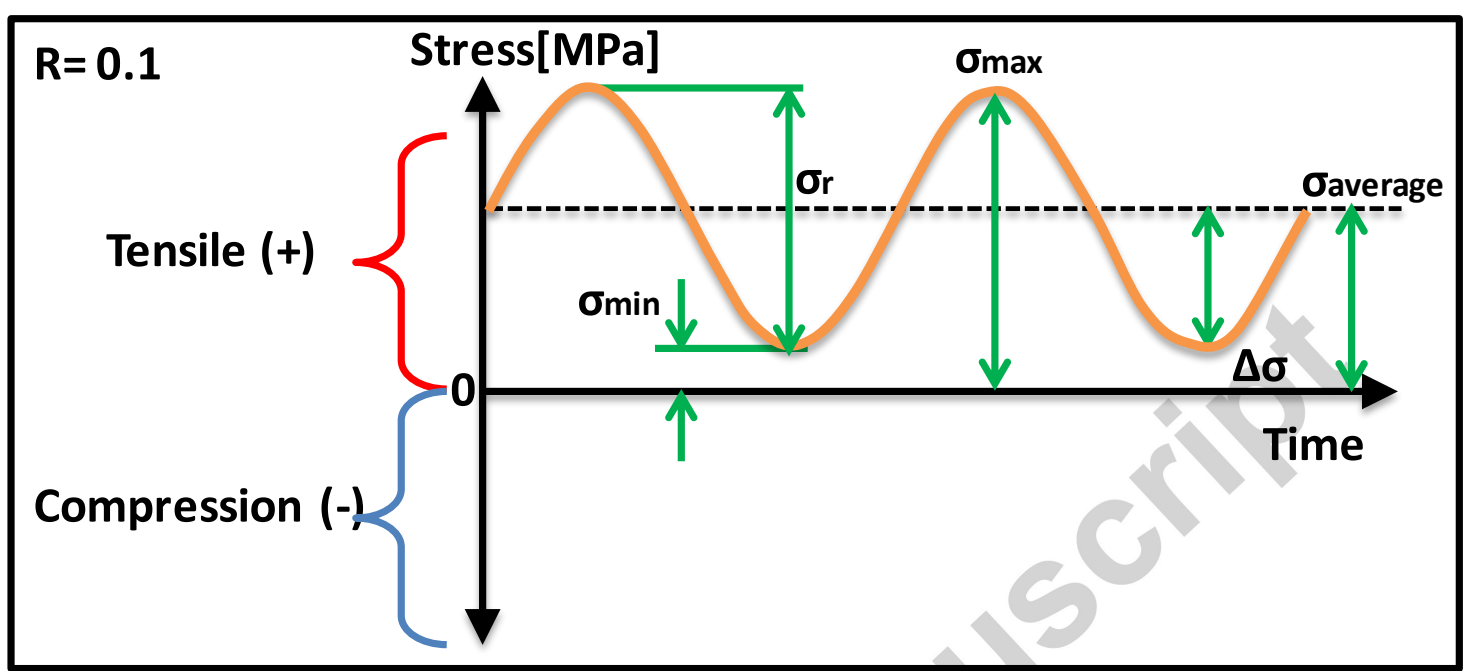

Figure 2. Description of the fatigue cycle used in this study. 

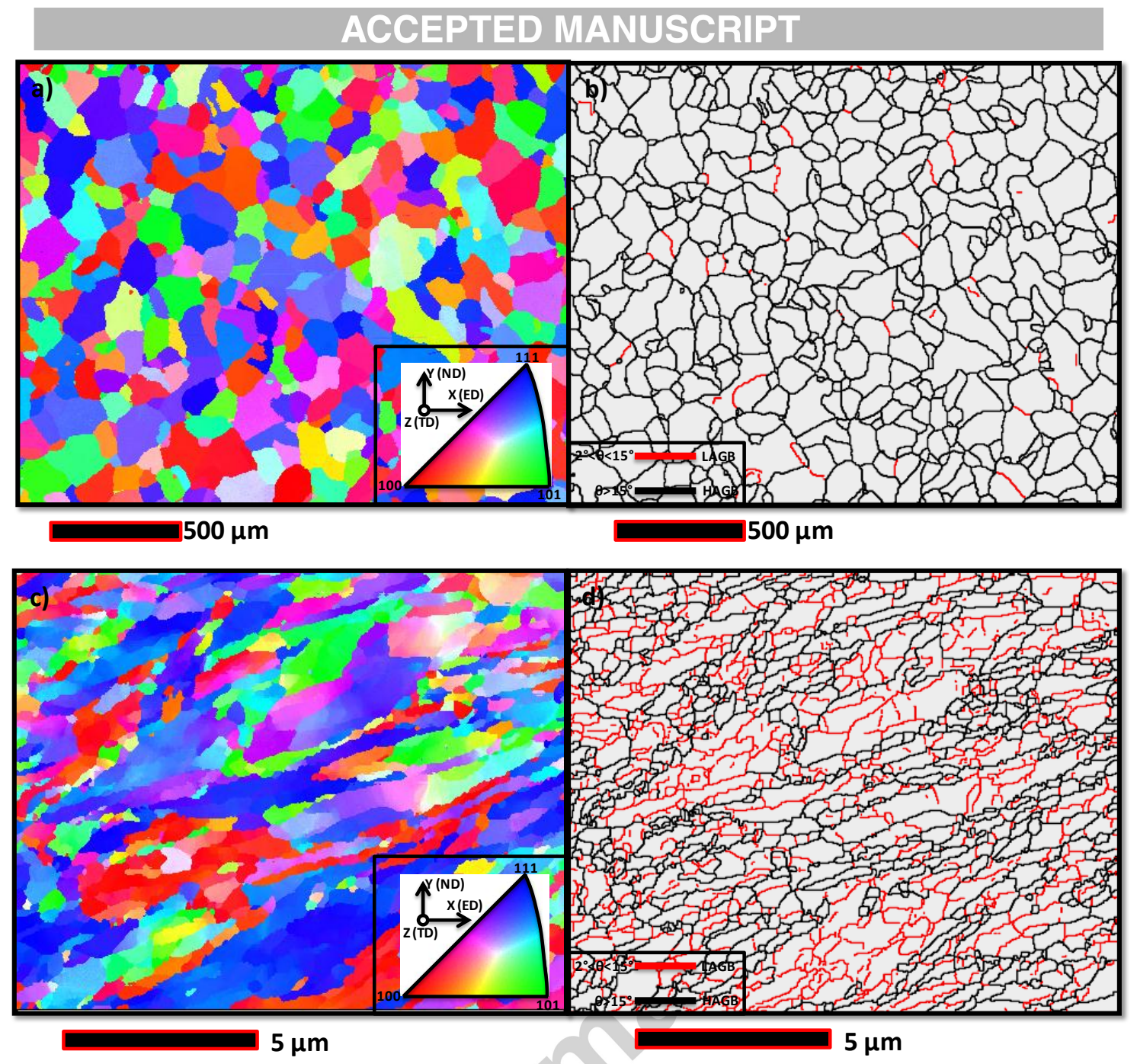

Figure 3. EBSD representation of the microstructures of the studied materials, a), b) 0 passes and c), d) 8 passes. a) and c) Inverse Pole Figure, b) and d) Grain boundary nature.

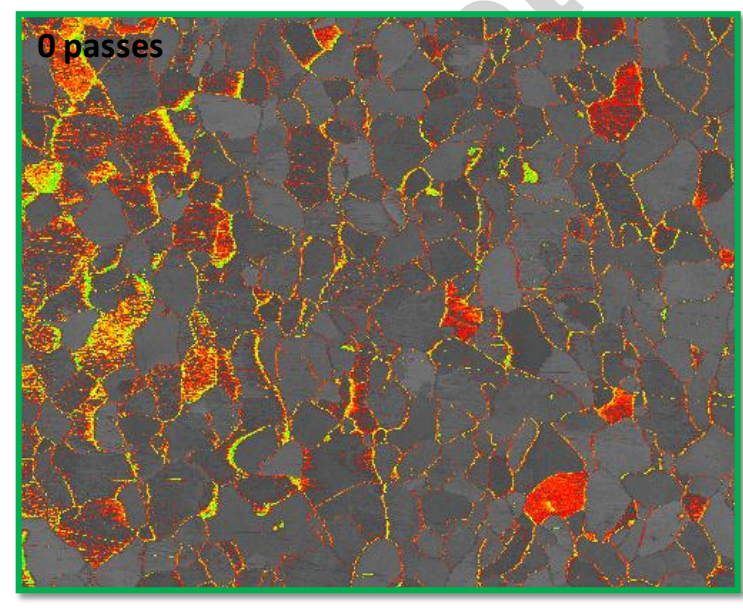

$500 \mu \mathrm{m}$

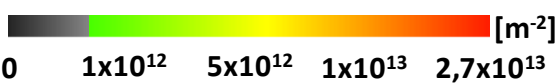

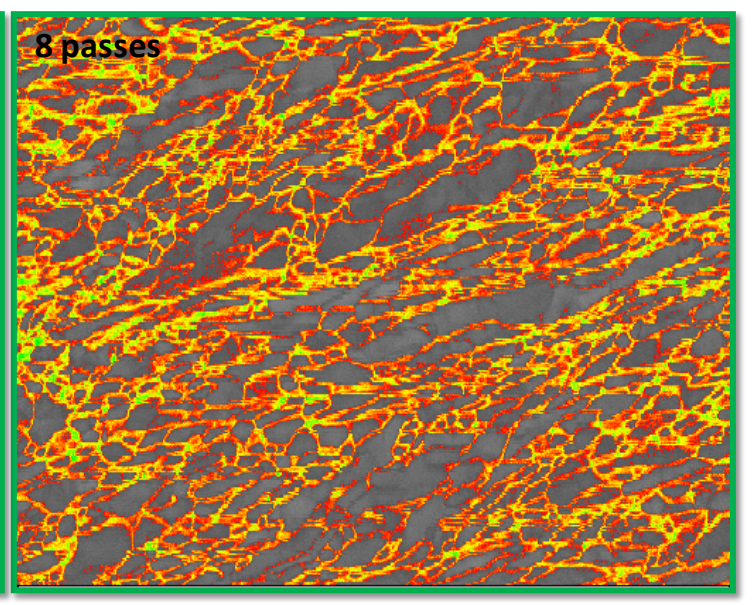

$5 \mu \mathrm{m}$

$\left[\mathrm{m}^{-2}\right]$

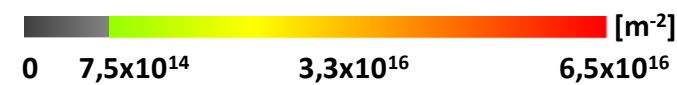

Figure 4. GNDs density maps for the two materials tested under fatigue. 

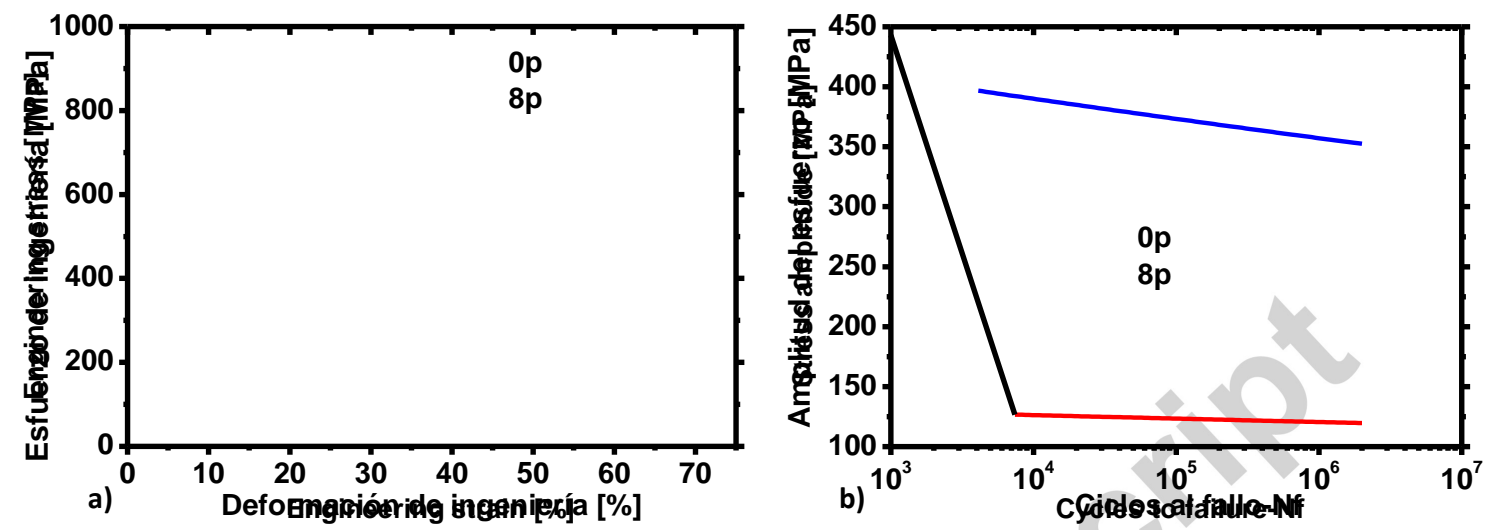

Figure 5. Mechanical properties of the materials: a) tensile tests b) fatigue tests.

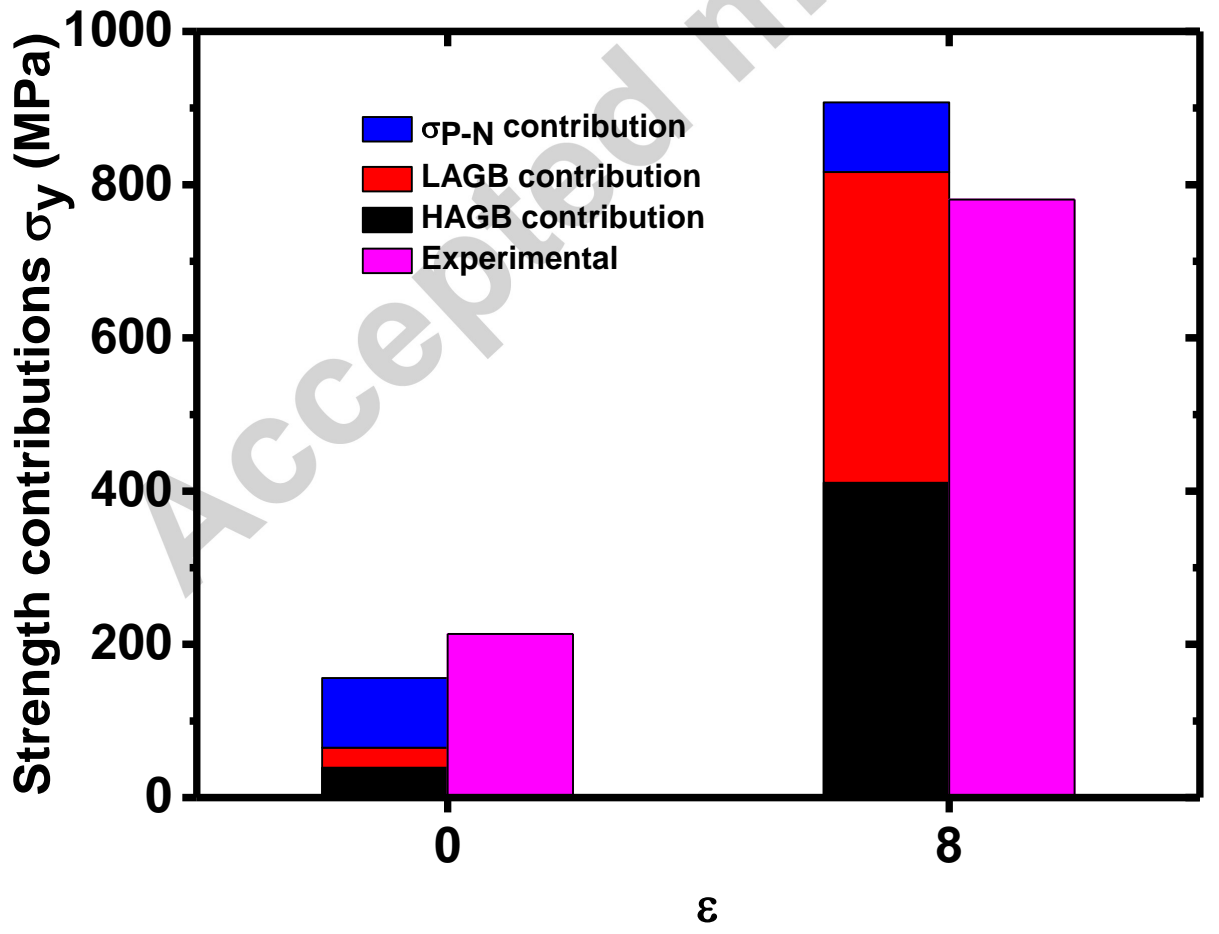

Figure 6. HAGB and LAGB strength contributions. 


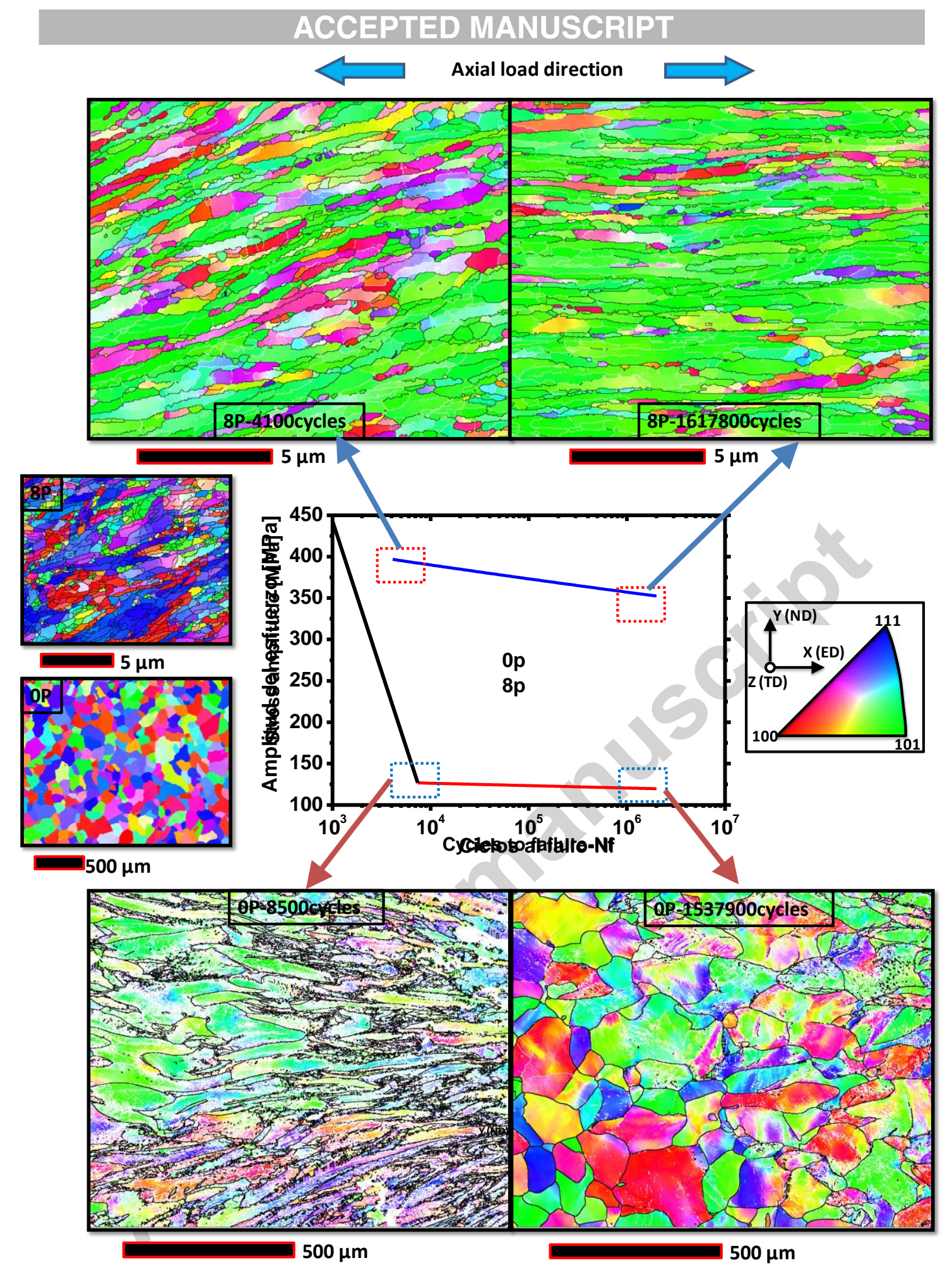

Figure 7. Microstructures before and after fatigue for different points over the S-N curve. 

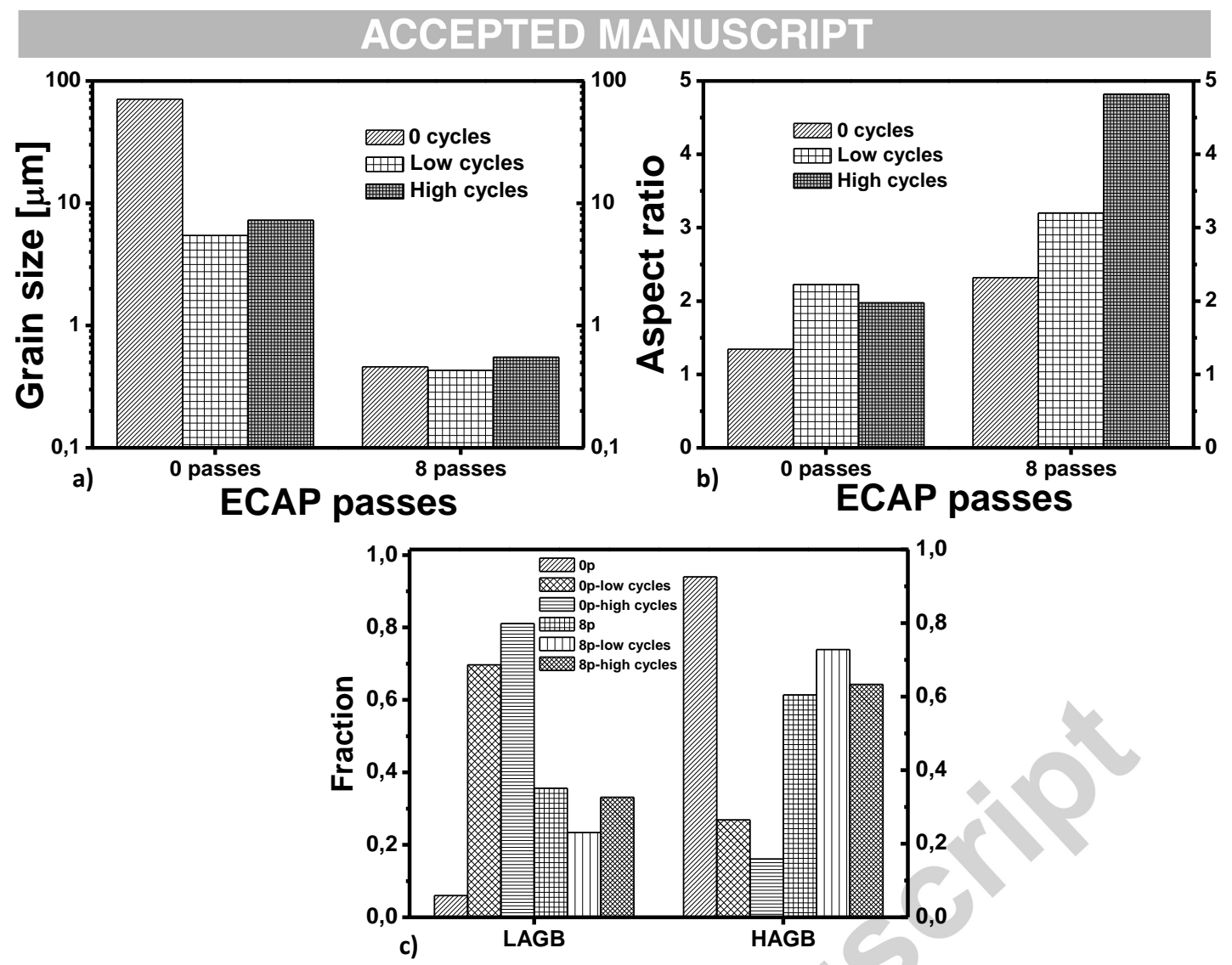

Figure 8. Microstructure properties: a) grain size evolution, b) aspect ratio and c) fraction of HAGB and LAGB. 

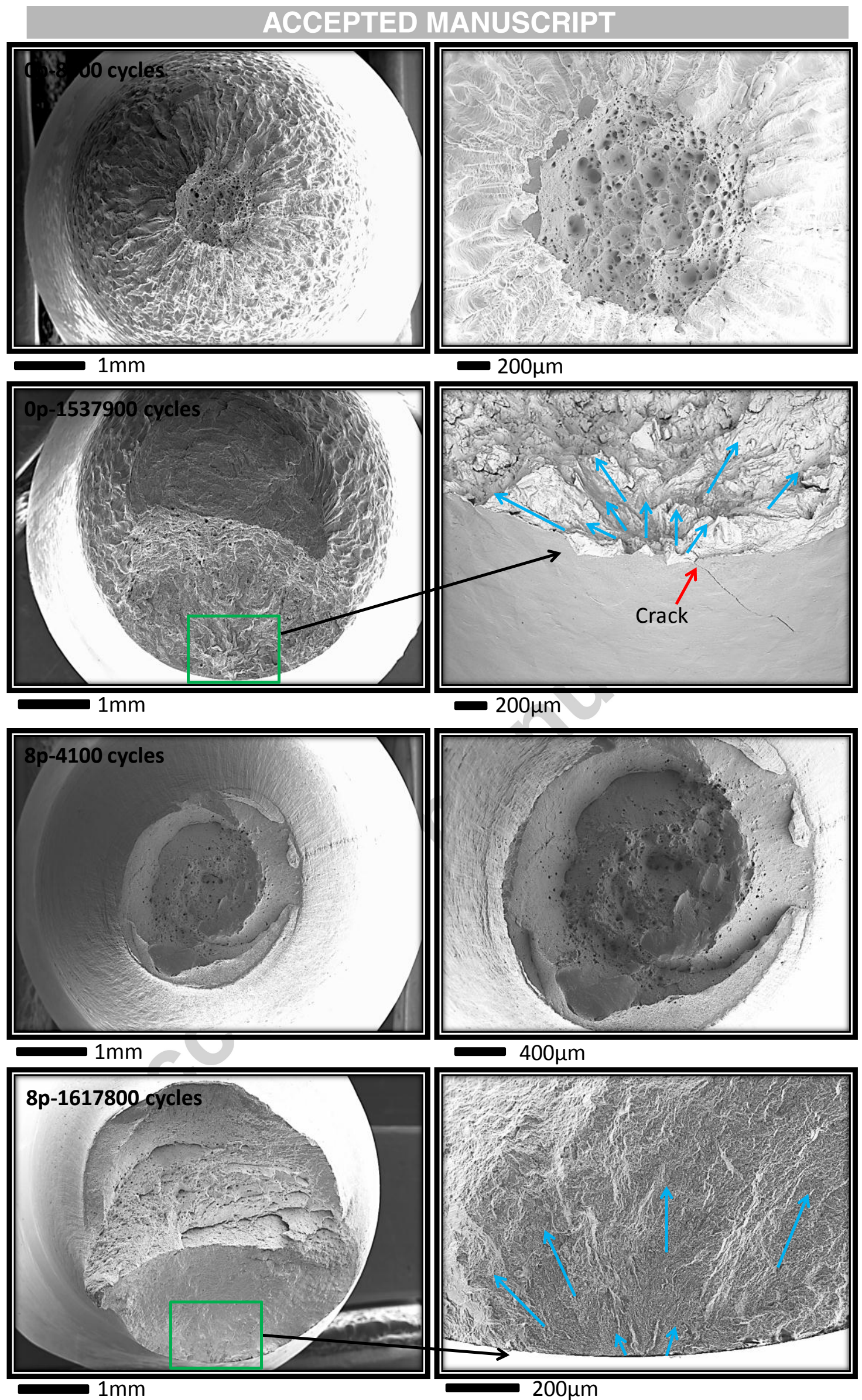

Figure 9. Fracture surfaces after the fatigue test. 


\section{ACCEPTED MANUSCRIPT}
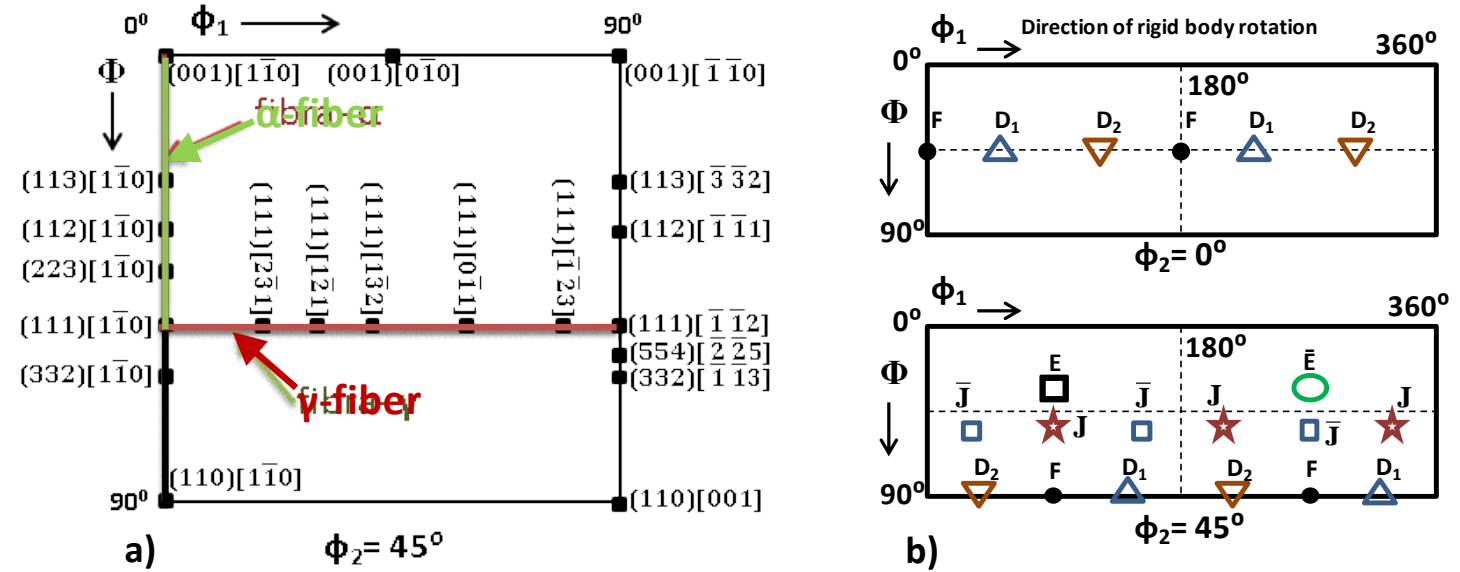

Figure 10. Ideal texture components for a) BCC materials and b) BCC materials deformed by simple shear. 

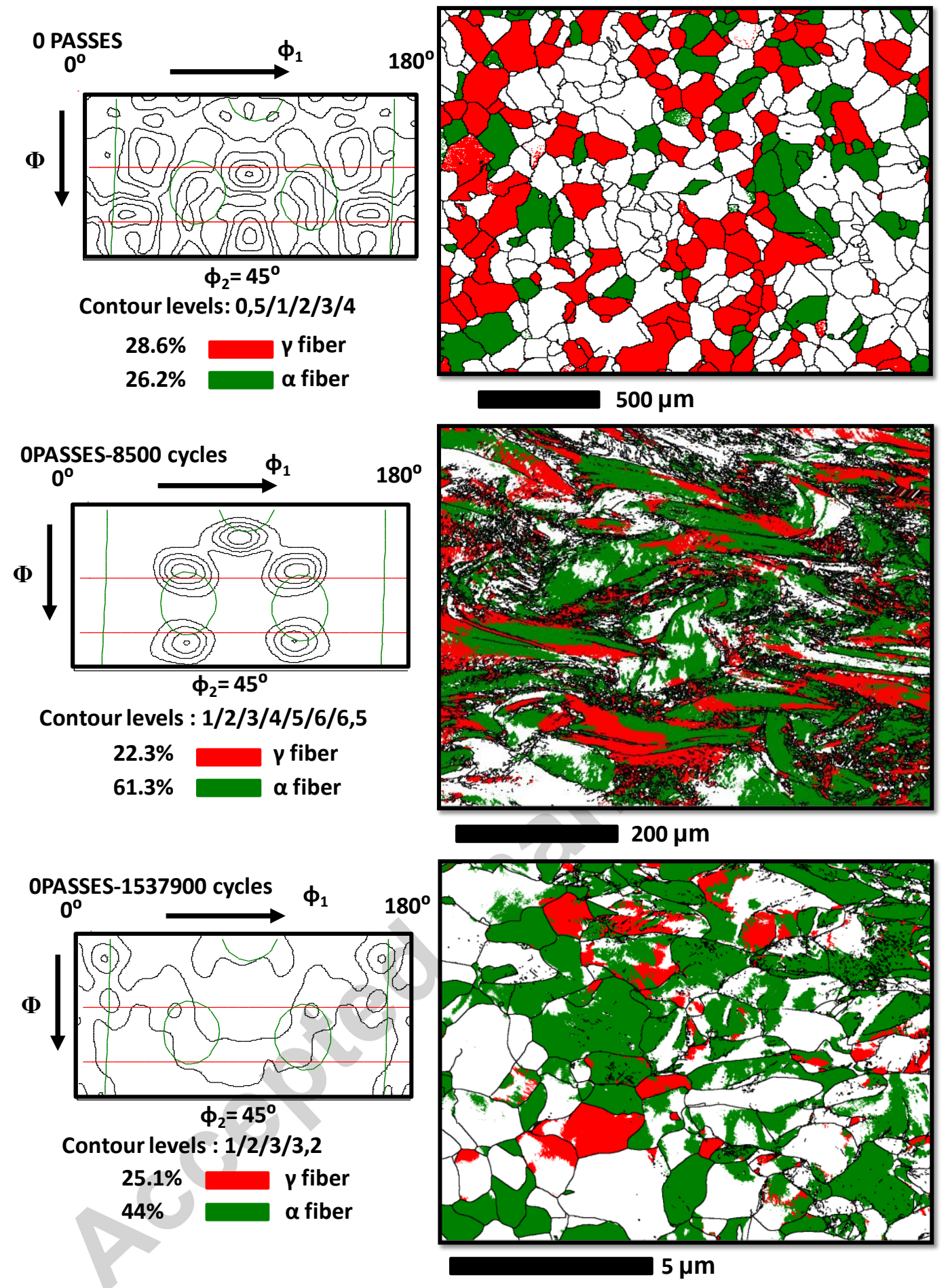

Figure 11. Texture evolution and microstructure representation of $\gamma$ and $\alpha$ fibers for the annealed material. 
ACCEPTED MANUSCRIPT
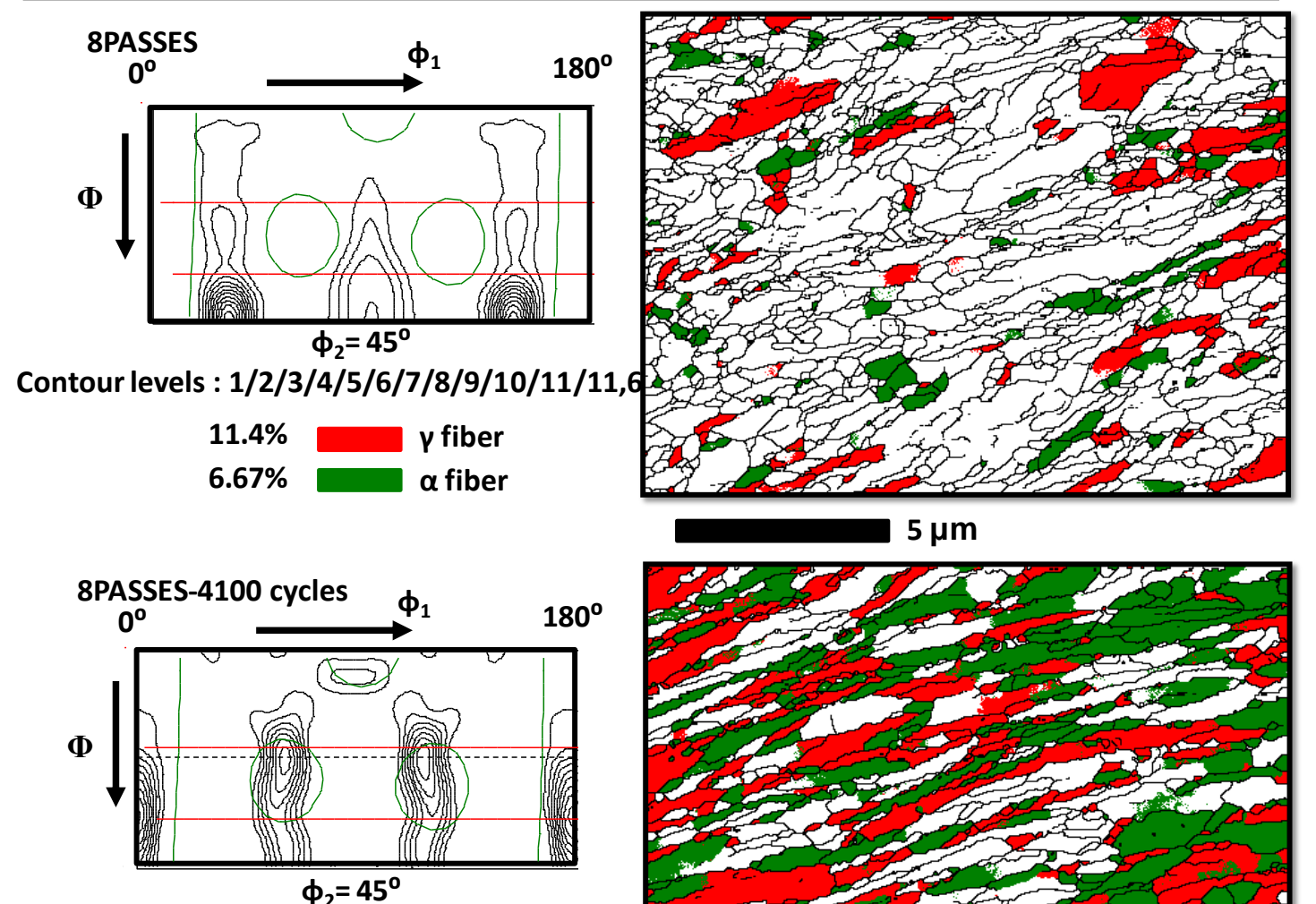

Contour levels : $1 / 2 / 3 / 4 / 5 / 6 / 7 / 8 / 9 / 9,4$

$33.2 \% \quad \gamma$ fiber

68.1\% $\alpha$ fiber
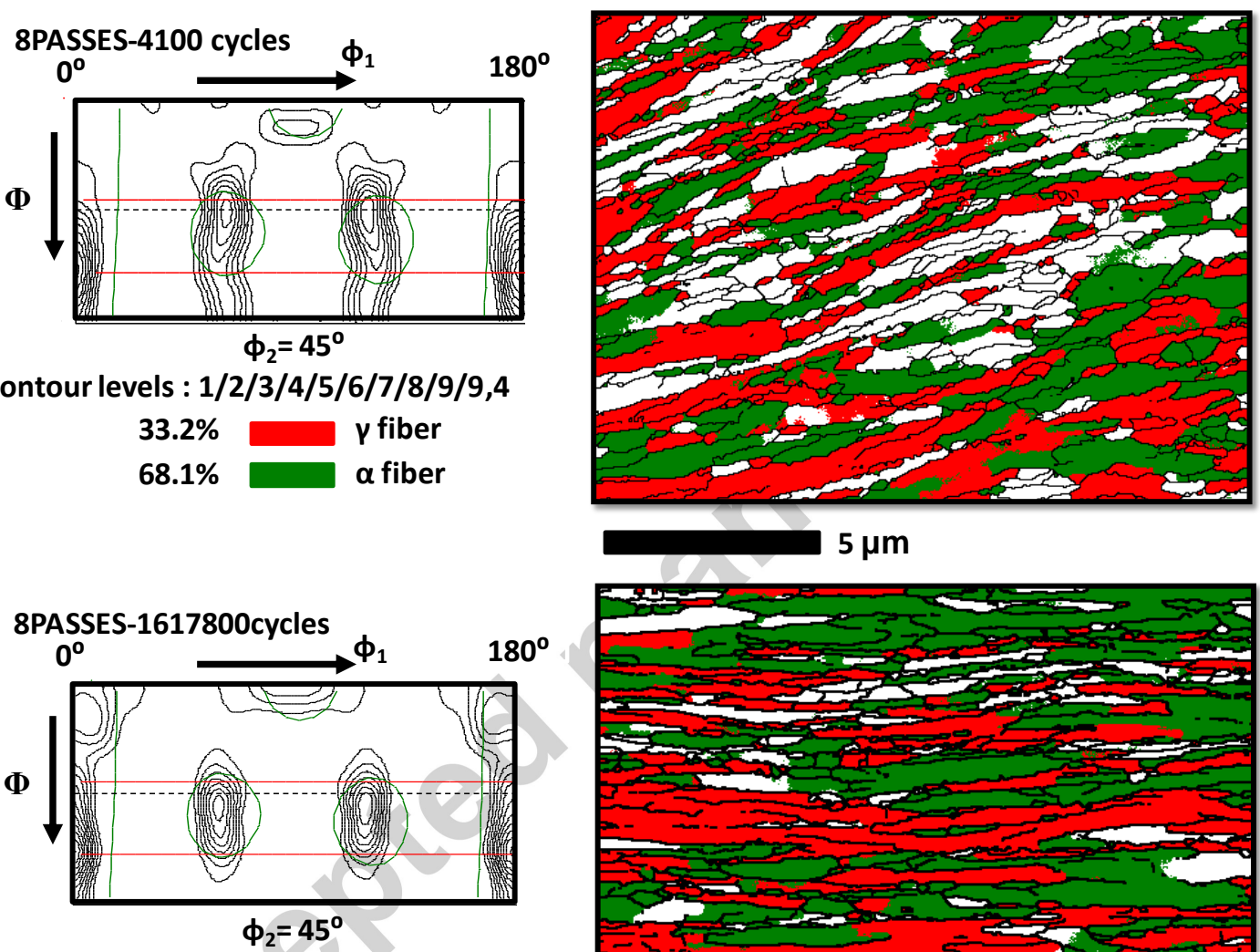

Contour levels : $1 / 2 / 3 / 4 / 5 / 6 / 7 / 8 / 9 / 10 / 11$
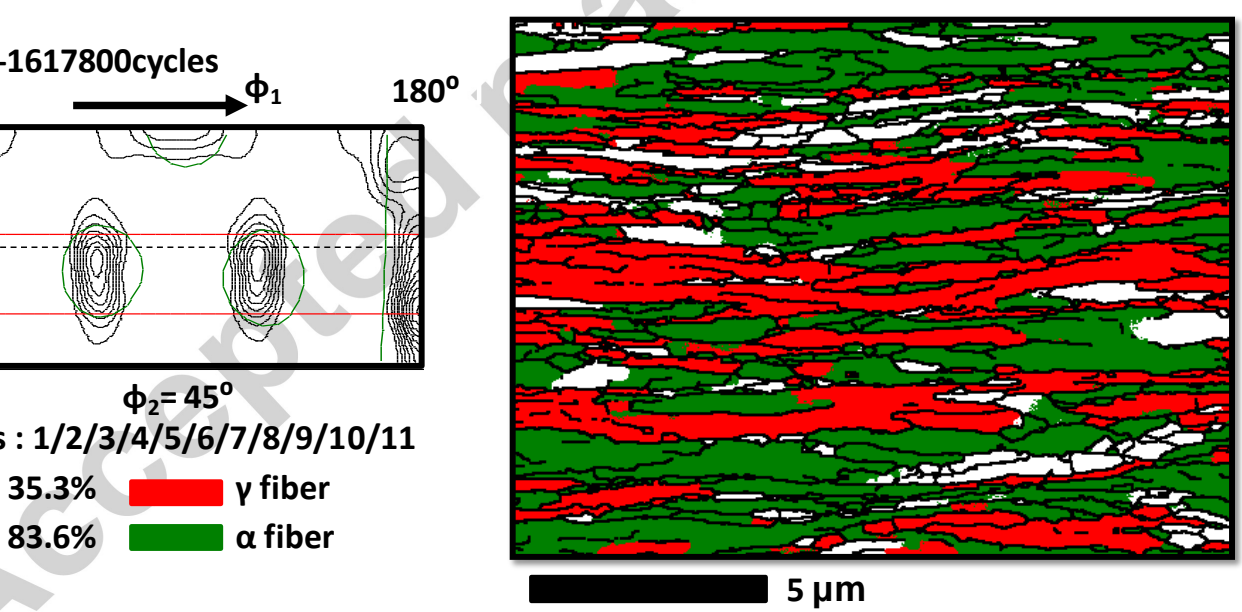

Figure 12. Texture evolution and microstructure representation of $\gamma$ and $\alpha$ fibers for the material processed by eight ECAP passes. 


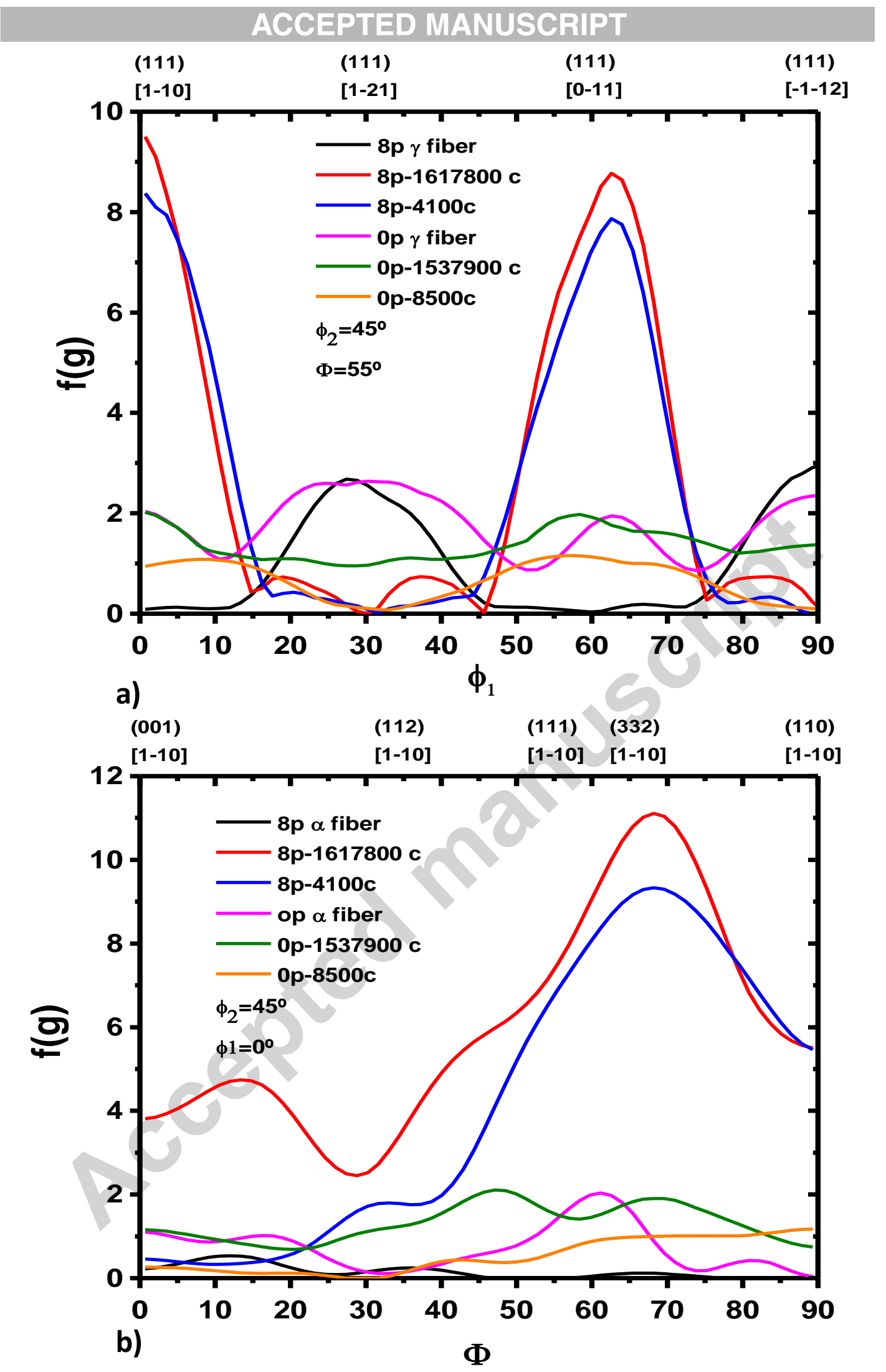

Figure 13. Orientation density $\mathrm{f}(\mathrm{g})$ for all the materials along, a) $\gamma$ fiber, $\mathrm{b}) \alpha$ fiber. 


\section{ACCEPTED MANUSCRIPT}

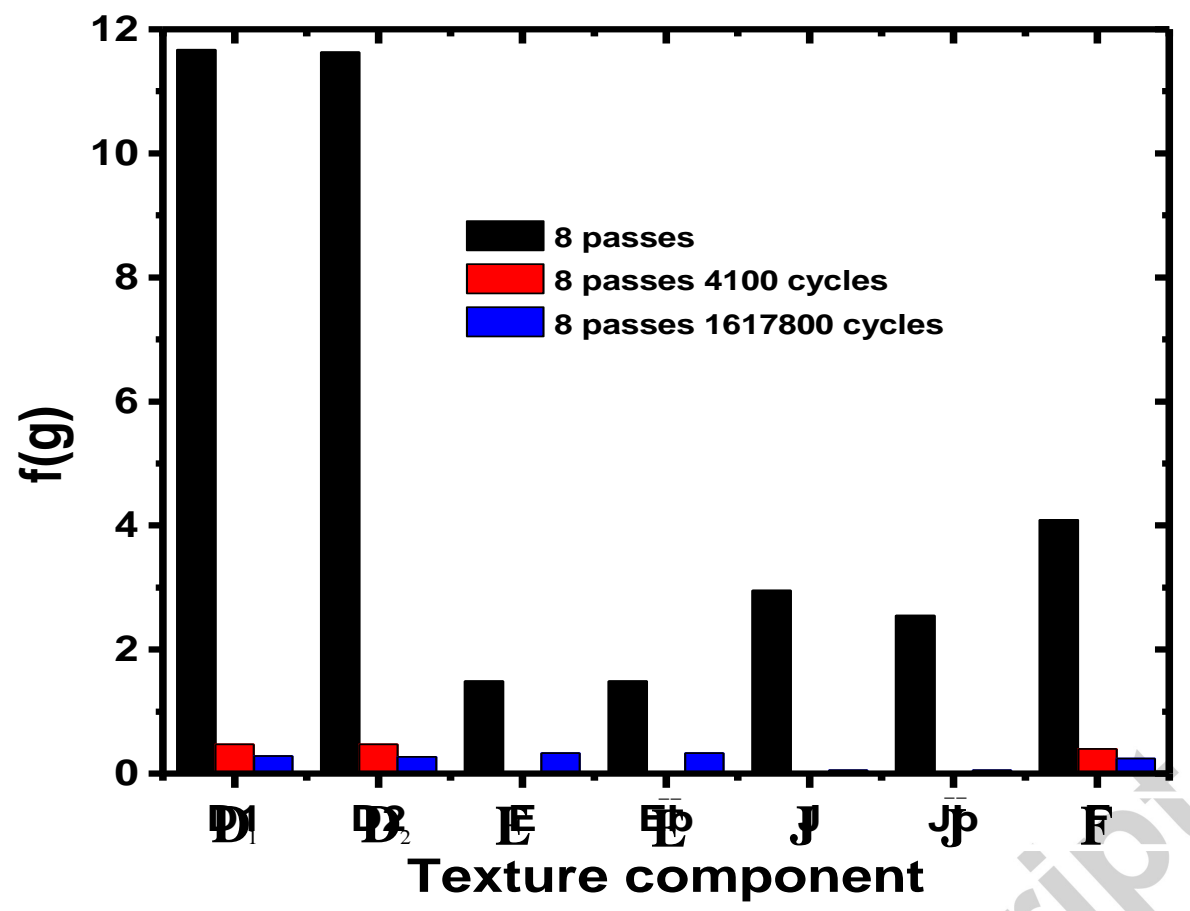

Figure 14. Orientation density $\mathrm{f}(\mathrm{g})$ of the simple shear components for the material with 8 ECAP passes before and after fatigue.

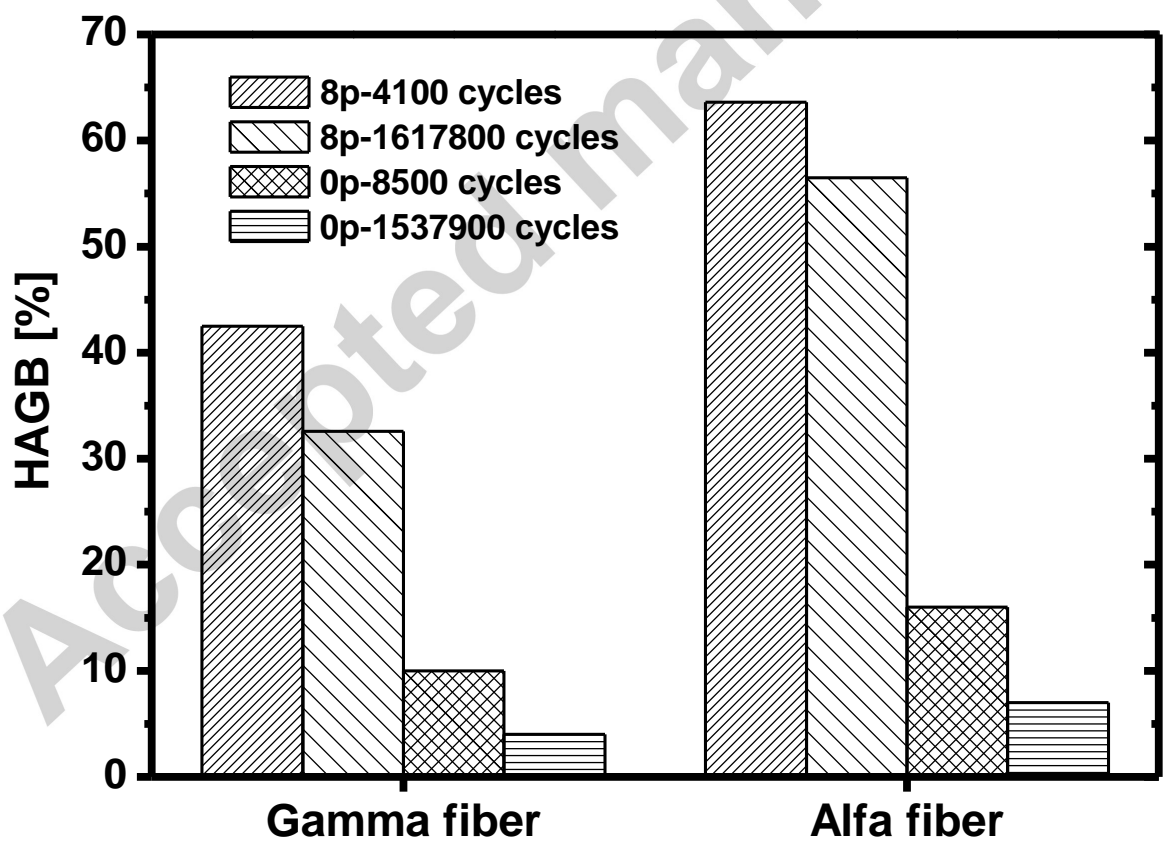

Figure 15. HAGB fractions in $\gamma$ fiber grains and in $\alpha$ fiber grains. 
Table 1. Strength contributions from HAGB and LAGB.

\begin{tabular}{|c|c|c|c|c|c|}
\hline $\begin{array}{c}\text { ECAP } \\
\text { passes }\end{array}$ & $\begin{array}{c}\text { f-HAGB } \\
{[\%]}\end{array}$ & $\begin{array}{c}\boldsymbol{\theta}_{\text {LAGB }} \\
{\left[{ }^{\circ}\right]}\end{array}$ & $\begin{array}{c}\rho_{\text {LAGB }} \\
{\left[\mathbf{m}^{-2}\right]}\end{array}$ & $\begin{array}{c}\sigma_{\mathrm{SGB}} \\
{[\mathrm{MPa}]}\end{array}$ & $\begin{array}{c}\sigma_{\mathrm{GB}} \\
{[\mathrm{MPa}]}\end{array}$ \\
\hline 0 & 95,4 & 0,64 & $9,99 \mathrm{E}+11$ & 26,05 & 39,1 \\
8 & 59,5 & 1,49 & $4,84 \mathrm{E}+14$ & 405,6 & 411 \\
\hline
\end{tabular}

Table 2. Basquin equation parameters.

\begin{tabular}{|c|c|c|}
\hline \multicolumn{3}{|c|}{ Basquin equation } \\
$\sigma=A * N_{f}^{-b}$ \\
\hline Material & $\boldsymbol{A}[\mathrm{MPa}]$ & $\boldsymbol{b}[\mathrm{MPa}]$ \\
\hline $0 p$ & 284,66 & $-0,069$ \\
$8 \mathrm{p}$ & 872,97 & $-0,07$ \\
\hline
\end{tabular}




\section{ACCEPTED MANUSCRIPT}

Table 3. Main ideal orientations in simple shear deformation of BCC materials .

\begin{tabular}{|c|c|ccc|}
\hline \multirow{2}{*}{ Notation } & $\multirow{2}{*}{\boldsymbol{h} \boldsymbol{k} \mid}<u v w>$ & \multicolumn{3}{|c|}{ Euler angles [ $\left.{ }^{\circ}\right]$} \\
\cline { 3 - 5 } & $(\overline{1} \overline{1} 2)[111]$ & $54,74 / 234,74$ & 45 & $0 / 90$ \\
\hline $\mathbf{D}_{1}$ & $(11 \overline{2})[111]$ & 125,6 & 90 & 45 \\
$\mathbf{D}_{2}$ & & $35,26 / 215,26$ & 90 & 45 \\
& $(110)[1 \overline{1} 1]$ & 90 & 35,26 & 45 \\
$\mathbf{E}$ & $(\overline{1} \overline{1} 0)[\overline{1} 1 \overline{1}]$ & 270 & 35,26 & 45 \\
$\overline{\mathbf{E}}$ & $(110)[1 \overline{1} 2]$ & $90 / 210$ & 54,74 & 45 \\
$\mathbf{J}$ & $(\overline{1} \overline{1} 0)[\overline{1} 1 \overline{2}]$ & $30 / 150 / 270$ & 54,74 & 45 \\
$\overline{\mathbf{J}}$ & $\{110\}\langle 001\rangle$ & $0 / 180$ & 45 & $0 / 90$ \\
$\mathbf{F}$ & & $90 / 270$ & 90 & 45 \\
\hline
\end{tabular}

